\title{
Family Capitals and Education Acquisitions: Analysis on the Mediating Effect of Shadow Education
}

\author{
Haiping Xue \\ Capital Normal University, Beijing 100048, China
}

\begin{abstract}
The purpose of this study is to explore whether family capitals and shadow education affect students' education acquisitions. The study constructs the social reproduction theory mode of family capitals influence on children's education acquisitions. Using 2014 Chinese education tracking data, this study examined shadow education's mediation effects on the process of family capitals affecting on education acquisitions for middle school students. Family capitals and shadow education jointly affect the education acquisitions of students, in which, shadow education plays an intermediary role between family capitals and education acquisitions for students. In sum, shadow education is increasingly becoming a supplement to school education and may become a new intermediary for family capitals influence on students' education acquisitions. The study adds to the limited literature in this particular field concerning the mediating effects of shadow education on family capitals and education acquisitions.
\end{abstract}

Keywords: Family capitals; Education acquisitions; Shadow education; Social reproduction; Mediation effect

Correspondence to: Haiping Xue, Professor and Director of the Institute of Educational Economics and Management, College of Education, Capital Normal University, China, Email: xuehaiping_416@163.com. 


\section{Research Background and Problem}

$\mathrm{F}$ AMILY socioeconomic background influence on education acquisitions is a major field of study, in China. When it comes to social equity research, many scholars in the country have examined the effects of family social, cultural, economic and political capital has on academic education opportunity acquisitions of children. It turns out that most students with higher family capitals have more chances to attain better academic education opportunities. Nowadays, there are plenty of Chinese compulsory education students participating in extracurricular tutoring, called "shadow education". Shadow education and school education complement each other and jointly influence students' education acquisitions. To date, the vast majority of empirical research on supplementary tutoring has only investigated the effects of family capitals/shadow education on academic education opportunity acquisitions. Also, empirical research combining school and shadow education outcomes concerning family capital and its related effects on student academic performance and higher-level education acquisitions is rare. Even fewer studies have explored the mediating effects of shadow education on students' education acquisitions under the affects of family capitals. This paper will establish a theoretical model using joint social reproduction to investigate how family capitals influence the mechanisms of students' education acquisitions through shadow education. At the same time, an examination of the mediating effects of shadow education on students' education acquisitions performed using family capitals will be conducted. From the perspective of shadow education, this paper plans to expand the research about family capitals and its effects on student education acquisitions. The results from this study will provide governments and education policy-makers another scientific theoretical reference for developing educational social equity initiatives.

This paper is divided into five parts: first, a review of relevant empirical studies; second, an introduction to data sources and variables to be used in the study; third, an explanation of the constructs and theoretical model for family capitals on education acquisitions; fourth, an introduction to the structural equation modeling (SEM) method to be used; and, fifth, a summary of results, discussion, and implications of this study.

\section{Review of Existing Research}

\section{Connotations and Classification of Family Capitals}

The concept of family capital was derived from the larger theories on social capital.

\footnotetext{
Funding: National Natural Science Foundation of China - "Family Capital, Shadow Education and Social Reproduction" Project (Approval Number: 71774112); National Natural Science Foundation of China -- "Facing the Shadow Education System: Research on Supplementary Tutoring in Compulsory Education in China" Project (Approval Number: 71373165).
} 
Xue. Family Capitals and Education Acquisitions.

Social capital in the modern era was first proposed in the late 1970s originating from the fields of social relations and social networks. French sociologist, Pierre Bourdieu, was one of the first researchers that devoted to systematically study the concept of social capital. In his view, "family" is the "cell" and basic unit of society. A family capital was seen as a means to providing various useful resources for educational activities for individual students.

Coleman (1988), an American scholar, divided family capitals into material, human and social capitals. Material capital refers to the material resources that can promote the development of production. Human capital applies to the knowledge level and ability that people possess to change the society. Lastly, social capital is a social resource structure that exists in the interpersonal network and can be used as an asset to help individuals achieve their goals. Social capital is believed to be found inside and outside of the family construct. More specifically, it is present in parentchild relationships, parents' concerns, expectations, supports, investments and participation in education of their children. Outside the family, concerns the interpersonal relationships within the community where the family is located.

According to Li Chunling (2003), family background mainly deals with the family's economic capital (family's income level), cultural (father's education level), social (father's position level) and political capitals (family's composition). Jiang Guohe and Yan Guangfen (2006) believed that family capitals mainly include family economic, cultural and social capitals. Liu Zhimin and Gao Yao (2011) understood family capitals as family socio-economic background, which included family economic, social, cultural and political capitals.

\section{Influence of Family Capitals on School Education Acquisition}

Coleman's (1988) work indicated that family social capital assists students to achieve higher education achievement. Teacherman (1987)'s study showed that social capital of American families measured by parents' occupation had an important influence on children's education prospects and academic performance in high school. Wong (1998) found that family social capital had a significant positive impact on children's academic achievement in his research from the Czech Republic. James (2000), using Australian survey data from 1991 to 1997, indicated that children from families with low social capital usually attended lower level colleges and universities.

In the 60 years from the 1940s to the 1990s, family social capital measured using the occupational status of fathers was viewed as an important impact on the student's education acquisition ( $\mathrm{Li}, 2003)$. This theory began to change, in the 1980s, when research began revealing that the higher the occupational levels of fathers resulted in the higher their children's academic performance. Li Yu (2006) found that from 1966 to 2003, family social capital measuring fathers' occupational status had different degrees of influence on the probability of their children going to high schools and colleges. During China's Great Cultural Revolution (1966-1976), family social capital had little influence on the probability of children attending school. In 
Xue. Family Capitals and Education Acquisitions.

the earlier years of educational reform (1977-1991), the family's social capital on the probability of children attending school began playing as a factor. In later years (1992-2003), the influence of family social capital rose steadily, to the point, which it performed as a significant indicator for university entrance. For instance, Liu and Gao (2011) study, using survey data of 14 university students from Jiangsu province, learned that the relationship between family capitals and higher education acquisition was a significant factor.

\section{Family Cultural Capital on School Education Acquisition}

Bourdieu (1989) indicated that children with higher cultural capital, in French families, received more and higher quality education. As well, Teacherman (1987) found that American parents with education degrees had a significant influence on their children's education and academic achievements in high school. Based on TIMSS data from Hong, South Korea, Japan, Singapore, and Thailand, Woessmann (2003) saw results indicating similar significant positive impact on students' performance. However, two studies, concluded otherwise, Robinson and Garnier (1985) and Katsillis and Rubinson (1990) found cultural capital to have little or no impact on student academic achievement.

\section{Family Economic Capital on School Education Acquisition}

American parents' incomes play an important factor on their children's education opportunities and academic performance in high school (Carneiro \& Heckman, 2002; Teacherman, 1987). Wong (1998), in a study done in the Czech Republic, found similar results indicating that family economic capital had a significant positive impact on students education achievement.

Li (2003) discovered that from the 1940-1970, family economic capital had a weak impact on individual education acquisition; but, had a significant impact on some special groups (such as rural and female populations). In the years, 1970-1990, the relationship between the two concepts would have a greater impact on all populations. An urban family survey indicated if the family's economic capital was at the top-tier in social class, the education level of their children was generally higher Guo \& Min, 2006). Finally, Liu \& Gao (2011) found that family economic income was a significant predictor of acquisition; but, had no significant impact on the quality of education acquisition.

\section{Family Political Capital on School Education Acquisition}

Bian, $\mathrm{Wu}$ and $\mathrm{Li}$ (2008), believed that political capital refers to the identity, power and resources provided by political parties and regimes, as well, as the deterrent and influence derived there from. $\mathrm{Li}$ (2003) uncovered that during the 1940s up until the 1990s, the influence of family political capital on personal education acquisition was divided with the first 30 years showing a positive relationship between concepts; 
Xue. Family Capitals and Education Acquisitions.

whereas, in the following 20 years, the influence of family political capital on children's education acquisition was just the opposite. Beginning in the 1990s, family political capital had no significant influence on individual education acquisition. Family political capital mainly played a role in the opportunity distribution of middle and higher education. Liu \& Gao (2011), observed that, if the father's political status was a member of the Communist Party of China, had a significant negative impact on the quantity of higher education acquisition of his children. Meanwhile, the father's national administrative level had also an insignificant impact on the quantity of higher education acquisition of his children. Moreover, the father's political status and national administrative level had a significant positive impact on the quality of his children's acceptance to higher education institutions.

\section{Family Capitals on Shadow Education Acquisition}

Research by Smyth (2009) on Irish families saw that with more social capital a family could afford more shadow education acquisition resulting in higher quality education for their children. Hong \& Zhao (2014) found that parental occupation hierarchy had a significant positive impact on whether urban compulsory education students participated in shadow education or not. Similar results were discovered in Zhou \& Zou (2016) review using PISA 2012 data that analyzed the influence of family social capital in China and the United States and how children's shadow education opportunity acquisition was impacted. Using a multi-layer linear model, results indicated that Chinese parents ranked at the highest occupational status index had significant positive opportunities for their children to getting supplementary tutoring in mathematics, reading and science; meanwhile, American parents in the highest occupational status index, would have no significant impact on their children receiving similar supplementary tutoring.

\section{Family Cultural Capital on Shadow Education Acquisition}

Tansel and Bircan-Bodur (2008) indicated that parents' education levels have a significant positive impact on supplementary tutoring expenditure for Turkish primary and secondary school students. A Chinese survey pointed out that the degree of education affects the head of a household significantly and on whether urban students participated in supplementary tutoring (Xue \& Ding, 2009). Parents' education degrees and expectations had significant positive impacts on whether Chinese primary and secondary school students participated in supplementary tutoring and compulsory education (Chu, 2009; Hong \& Zhao, 2014; Mark Bray et al., 2014; Xue, 2015). However, other studies found differing results, education degrees and education expectations on the part of parents had no significant influence on whether students participated in shadow education (Buchmann et al., 2010; Zeng et al., 2010).

\section{Family Economic Capital on Shadow Education Acquisition}


Stevenson and Baker (1992) conducted a pioneering research on shadow education and discovered that family economic capital had a significant impact on whether Japanese high school students participated in supplementary tutoring, which eventually led to a more likely chance of attending university for these particular students. Other studies discovered parallel findings, such as, family income significantly impacting supplementary tutoring (Bircan, 2008; Buchmann et al., 2010; Tansel and Bircan, 2008; Xue \& Ding, 2009). On the other hand, a survey completed in Gansu, Hunan, and Jiangsu provinces, Zeng et al. (2010) found that the monthly income of fathers has no significant impact on whether junior high school students chose supplementary tutoring. Xue's (2015) study, also done in China, found similar results showing that net household income per capita of a family had no significant influence on whether students participated in supplementary tutoring.

\section{Influence of Shadow Education on School Education Acquisition}

Family capitals directly influence the students' school and shadow education acquisitions and, at the same time, students' shadow education acquisitions influence their school education acquisitions. Since students' shadow education will be helpful for them to improve their academic performance, also will position them favorably for higher education success.

Studies on the influence of shadow education acquisition on school education acquisition have basically centered on the influence of shadow education acquisition on students' academic performance at school. Due to the influence of individual, family, school, and other factors on students' academic performance, in order to control the endogenous problems, some scholars, in China, and abroad have adopted advanced statistical methods to estimate the influence of supplementary tutoring on students' academic performance. These studies, so far, have presented mixed results.

Sunderman (2006) attempted to estimate the influence of supplementary tutoring on Indonesian fourth-graders by using the instrumental variable method and found that the influence was not significant. As well, Dang (2007), made use of the instrumental variable method and using such data as the hourly after-class tuition fees paid by parents predicted the positive impact on student learning. ZHAO (2015), making use of the instrumental variable method, also, found that after-school tutoring expenditures, though small, showed an impact on the math performance. Yet, studies from Guill and Bonsen (2010), using a multilayer linear model to observe the influence of supplementary tutoring on grade 5 and 6 students, in Hamburg, Germany, saw no significance in student learning. Zhang (2013) and Hu et al. (2015) studies had similar findings.

\section{Summary of Existing Research}

Scholars have paid extensive attention to the influence of family capitals on education opportunity acquisition in schools and most of the relevant research concludes 
that family capitals is an important influence on student learning. With the rise of shadow education, the influence of family capitals on shadow education acquisition has only begun to attract the attention of scholars, in recent years. Related studies tended to focus on the influence of family cultural capital and economic capital on the opportunity acquisition of shadow education, and rarely discussed the influence of family social capital and political capital. At present, in the compulsory educational system now present in China, shadow and school education complement each other.

The vast majority of existing studies focused mainly on the family capitals impact on school education acquisition or shadow education acquisition. Few studies combined school education and shadow education to investigate the influence of family capitals on the students' academic performance and higher-level education acquisition. As well, few studies investigated the mediating effects of shadow education on the influence of family capitals, students' performance, and the acquisitions of higher-level education.

\section{Data Source and Variable Description}

The data used in this study came from the 2014 China Education Panel Survey (CEPS) conducted by the China Survey and Data Center of Renmin University of China. The variables used in the statistical analysis are described in Table 1. The variables of extracurricular tutoring in the dataset refer to the education activities of academic course supplements. The sample number of junior high school students in this data set was 19,487 .

According to the literature research results from above, this study, divides family capitals into four capital categories: social, cultural, economic and political. Family social capital measurements come from Li Chunling's research on occupational stratification, which divides the occupation of students' parents into upper, middle and lower levels. The parent with the higher occupational stratification was used to measure the index of student's social capital outside the family. The higher the occupational stratification of the parent, the more social capital outside the family the student attained. ${ }^{\text {IC }}$ ultural capital is measured by the number of books in the family, outside of the parent's highest education and textbooks and magazines. Economic capital is measured by family financial status, which can be divided into three levels: difficult, medium and rich. Political capital is measured by parents' political status, which can be divided into three categories ${ }^{2}$ : party members, democratic parties and the masses.

From previous literature, education acquisitions of students mainly referred to the level and quality of education acquired by students. Generally, the difference of education acquisitions of students can be measured from two dimensions. One is the level of education received by students or the number of years receiving education, which represents the difference of education acquired by students. Second, to measure the education obtained by students is the difference in education quality under the 
same education level or years, usually measured by students' grades or school quality. Although the quantity and quality of education are both important measures of education acquisition, in studies of family capitals and student's education acquisitions, affected by data availability, the researchers always paid much more attention to the number than to the quality of education acquisition. Most studies were not involved in aspects of the difference of quality education, which may be because the quality of education information data is difficult to collect. Different from existing studies, this paper will mainly focus on the influence of family capitals on quality of students' education acquisitions, which is measured by students' academic performance at school. The variables involved in the article are described in Table 1 below.

\section{Theoretical Construction Model of the Influence of Family Capitals on Edu- cation Acquisition}

According to existing literature studies, family capitals has an important impact on acquisitions of school education and shadow education; but few studies combine them to investigate the impact of family capitals on education acquisitions of children. It will underestimate the influence of family capitals on children's education acquisitions if they are investigated separately, and the mechanisms by which family capitals affect children's education acquisitions will also not be fully revealed. In order to fully and accurately evaluate the influence of family capitals on children's education acquisitions, this study, combined school education and shadow education to construct a theoretical model of the influence of family capitals on children's education acquisitions. Based on Li's (2006) study on the mechanisms of education inequality and Liu \& Gao's (2011) study on the mechanisms of family capitals influences on acquisition of higher education quantity and quality, this study, constructs the theoretical model of family capitals impact on acquisition of education (see Figure 1). Firstly, family capitals can directly influence children's academic achievement at school. Secondly, family capitals can also influence their children's academic performance at school by influencing the child's access to education opportunities (for example, go to a better school) (see corresponding solid arrows in Figure 1). Thirdly, family capitals can also influence their children's academic performance at school by influencing their shadow education opportunity advantage (see corresponding dotted arrows in Figure 1). Finally, advantage opportunity in children's school education acquisitions will also affect their advantage opportunity acquisitions in shadow education (see corresponding part of the dotted line arrow in the Figure 1).

The mechanism faction that family capitals affects is their children's education acquisitions that are essentially a mechanism of resource exclusion, meaning that the advantage class families use their family capital advantage to reduce competition for entrance, or to exclude some competitors from the competition so to increase opportunities of accessing high-quality school education and shadow education. This kind of exclusion is embodied in four types: economic resource, privileged resource, implicit resource, and cultural resource. Economic resource exclusion, which is the 
most common form in modern society, mainly refers to the rich class's exchange of family economic capital for high-quality education resources. Privileged resource exclusion refers to the fact that in the design of education system, special positions are always reserved for some privileged classes. The setting of high-quality education resources often favors some privileged classes. Implicit exclusion of resources means that when making decisions on admission to higher education and shadow education, vulnerable class families have to withdraw from competition for shadow and better school education opportunities due to their poor abilities to bear the risk of low evaluation on the expected return of education. Lastly, the exclusion of cultural resources indicates that families with parents, who have low educational backgrounds and poor cultural resources, do not attach great importance to their children's education, so therefore they may withdraw from the competition for shadow and better school education opportunities.

Based on the theoretical model of family capitals influencing education, in order to test the mediating effect of shadow education on family capitals and education acquisition, the following research hypotheses are as follows:

Hypothesis 1: Family capitals have a significant positive impact on education acquisitions of junior high school students.

Hypothesis 2: Whether participation in shadow education has a significant positive impact on education acquisitions of junior high school students.

Hypothesis 3: Shadow education plays an intermediary role in the process of family capitals influence on students' education acquisitions, that is, family capitals influences students' education acquisitions by influencing their shadow education participation opportunities.

\section{Analysis of the Mediating Effect of Shadow Education}

Based on the theoretical model and research hypothesis established, this study will use structural equation models to analyze influences of family capitals to students' education acquisitions and test mediating effects of family capitals to students' education acquisitions through shadow education.

\section{Intermediary Model of Family Cultural Capital on Students' Education Acqui- sitions}

Using the theoretical model and Wen et al.'s research to verify the methods and procedures for mediating effects, this study constructs an intermediary model for family cultural capitals impact on students' education acquisitions (the normalized regression path coefficient results of the model are shown in Figure 2). Results indicated that the path coefficients passed the significance level test except for the path coefficient of shadow education participation affects to students' performance. According to the joint significance test, the mediating effect of family cultural capital to students' achievements is not significance; shadow education does not play an intermediary role between family cultural capitals and students' performance. 
Xue. Family Capitals and Education Acquisitions.

\section{Table 1. Description of Variables in Statistical Analysis.}

\begin{tabular}{|c|c|c|c|}
\hline $\begin{array}{l}\text { Variable } \\
\text { Type }\end{array}$ & \multicolumn{2}{|c|}{ Variable Name } & Variable Description \\
\hline $\begin{array}{l}\text { Shadow } \\
\text { Education }\end{array}$ & \multicolumn{2}{|c|}{$\begin{array}{l}\text { Whether to participate in extracur- } \\
\text { ricular tutoring }\end{array}$} & $0=$ No, $1=$ Yes \\
\hline $\begin{array}{l}\text { Education } \\
\text { Acquisition }\end{array}$ & \multicolumn{2}{|c|}{ Student achievement } & $\begin{array}{l}\text { The total score of standardized scores of stu- } \\
\text { dents in the mid-term examination of foreign } \\
\text { languages and numerals in } 2013\end{array}$ \\
\hline \multirow{6}{*}{$\begin{array}{l}\text { Family } \\
\text { Capitals }\end{array}$} & $\begin{array}{l}\text { Social } \\
\text { capital }\end{array}$ & $\begin{array}{l}\text { Parents have the } \\
\text { highest career stratifi- } \\
\text { cation }\end{array}$ & $1=$ lower, $2=$ middle, $3=$ upper \\
\hline & \multirow{3}{*}{$\begin{array}{l}\text { Cultural } \\
\text { capital }\end{array}$} & $\begin{array}{l}\text { Highest degree of } \\
\text { parents }\end{array}$ & $\begin{array}{l}1=\text { illiteracy, } 2=\text { primary school, } 3=\text { junior high } \\
\text { school, } 4=\text { high school, } 5=\text { junior college, } 6= \\
\text { university undergraduate, } 7=\text { graduate student } \\
\text { and above }\end{array}$ \\
\hline & & $\begin{array}{l}\text { Books, magazines } \\
\text { outside the family } \\
\text { library }\end{array}$ & $1=$ little, $2=$ less, $3=$ average, $4=$ more, $5=a$ lot \\
\hline & & $\begin{array}{l}\text { Parents' expectations } \\
\text { of their children's edu- } \\
\text { cation level }\end{array}$ & $\begin{array}{l}1=\text { don't read now, } 2=\text { junior high school gradua- } \\
\text { tion, } 3=\text { high school, } 4=\text { junior college, } 5=\text { Big } \\
\text { Ben, } 6=\text { graduate student, } 7=\text { doctor }\end{array}$ \\
\hline & $\begin{array}{l}\text { Economic } \\
\text { capital }\end{array}$ & Family financial status & $1=$ difficult, $2=$ medium, $3=$ rich \\
\hline & $\begin{array}{l}\text { Political } \\
\text { capital }\end{array}$ & $\begin{array}{l}\text { Political status of par- } \\
\text { ents }\end{array}$ & $\begin{array}{l}1=\text { communist party member } 2=\text { Democratic } \\
\text { Party } 3=\text { masses }\end{array}$ \\
\hline \multirow{2}{*}{$\begin{array}{l}\text { Individual } \\
\text { Factors }\end{array}$} & \multicolumn{2}{|l|}{ Gender } & $0=$ female, $1=$ male \\
\hline & \multicolumn{2}{|l|}{ Grade } & $0=$ seventh grade, $1=$ ninth grade \\
\hline
\end{tabular}

Table 2. Fitting Results of the Intermediary Model of Family Cultural Capital Influencing Students' Education Acquisitions.

\begin{tabular}{llllllllll}
\hline Fitting Index & CMIN & DF & CMIN/DF & RMSEA & NFI & RFI & IFI & TLI & CFI \\
\hline Numerical & 358.10 & 12 & 29.84 & 0.038 & 0.967 & 0.922 & 0.968 & 0.925 & 0.968 \\
\hline $\begin{array}{l}\text { Judgment } \\
\text { Standard }\end{array}$ & & & $<5.0$ & $<0.10$ & $>0.90$ & $>0.80$ & $>0.90$ & $>0.80$ & $>0.90$ \\
\hline
\end{tabular}

Table 3. Results of the Intermediary Model - Family Social Capital Influencing Students' Education Acquisitions.

\begin{tabular}{llllllllll} 
Fitting Index & CMIN & DF & CMIN/DF & RMSEA & NFI & RFI & IFI & TLI & CFI \\
\hline Numerical & 140.01 & 5 & 28.00 & 0.034 & 0.957 & 0.919 & 0.959 & 0.875 & 0.959 \\
\hline $\begin{array}{l}\text { Judgment } \\
\text { Standard }\end{array}$ & & & $<5.0$ & $<0.10$ & $>0.90$ & $>0.80$ & $>0.90$ & $>0.80$ & $>0.90$ \\
\hline
\end{tabular}


Xue. Family Capitals and Education Acquisitions.

Table 4. Results of the Intermediary Model - Family Economic Capital Influ-

encing Students' Education Acquisitions.

\begin{tabular}{llllllllll}
\hline Fitting Index & CMIN & DF & CMIN/DF & RMSEA & NFI & RFI & IFI & TLI & CFI \\
\hline Numerical & 59.38 & 5 & 11.87 & 0.02 & 0.970 & 0.910 & 0.972 & 0.917 & 0.972 \\
\hline $\begin{array}{l}\text { Judgment } \\
\text { Standard }\end{array}$ & & & $<5.0$ & $<0.10$ & $>0.90$ & $>0.80$ & $>0.90$ & $>0.80$ & $>0.90$ \\
\hline
\end{tabular}

Table 5. Results of the Intermediary Model - Family Political Capital Influencing Students' Education Acquisitions.

\begin{tabular}{llllllllll} 
Fitting Index & CMIN & DF & CMIN/DF & RMSEA & NFI & RFI & IFI & TLI & CFI \\
\hline Numerical & 59.47 & 5 & 11.89 & 0.02 & 0.964 & 0.892 & 0.967 & 0.900 & 0.967 \\
\hline $\begin{array}{l}\text { Judgment } \\
\text { Standard }\end{array}$ & & & $<5.0$ & $<0.10$ & $>0.90$ & $>0.80$ & $>0.90$ & $>0.80$ & $>0.90$ \\
\hline
\end{tabular}

Table 6. Results of the Intermediary Model - Family Capitals Influencing Students' Education Acquisitions.

\begin{tabular}{llllllllll}
\hline Fitting Index & CMIN & DF & CMIN/DF & RMSEA & NFI & RFI & IFI & TLI & CFI \\
\hline Numerical & 1136.66 & 2 & 35.52 & 0.042 & 0.950 & 0.914 & 0.951 & 0.916 & 0.951 \\
\hline $\begin{array}{l}\text { Judgment } \\
\text { Standard }\end{array}$ & & & $<5.0$ & $<0.10$ & $>0.90$ & $>0.80$ & $>0.90$ & $>0.80$ & $>0.90$ \\
\hline
\end{tabular}

The results show that the model is recursive, with a sample size of 19487 (the results of model fitting are shown in Table 2). It can be seen from the table that all other fitting indexes reach a good level except for $\mathrm{CMIN} / \mathrm{DF}=29.84>5$, this indicates that the model can fit well with the actual observation data and the established model for family cultural capital influencing education acquisition. In all, the theoretical hypothesis model is stable. The likeliest reason why CMIN/DF $>5$ rejects theoretical model 1 is the large number of valid samples $(\mathrm{N}=19,487)$. When the sample size is very large, all the models that fit well with the data will be rejected, so whether to use the model cannot be decided through a chi-square test. Fitting index cannot be the main basis for comparing models, instead, the rationality of the relationships between variables described in models and the appropriateness of parameters' estimation should be considered (for example, the correlation coefficient cannot be greater than 1 , and the error variance cannot be a negative number). The relationship between variables described in this model is reasonable and the parameters' estimation is appropriate. Therefore, this study decided to use this model to test the mediating effect of family cultural capitals on students' education through shadow education. 


\section{Intermediary Model of Family Social Capital Influence on Students' Education Ac- quisitions}

For family capitals influence on education acquisition, this study, constructed the intermediary model that family social capital influences education acquisitions of students. All the path coefficients in the model past the significance level test (the results of standardized regression path coefficient of the model are shown in Figure 3). According to the joint significance test, family social capital has a significant mediating effect on students' performance and shadow education plays a partial mediating role between family social capital and students' performance.

The results display a model that is recursive at a sample size of 19,487 (Table 3). Except for CMIN/DF $=28.00>5$, all other fitting indexes reached a good fit level indicating that the model can be well fitted with the actual observation data. The relationships between variables described in this model were reasonable and the parameters' estimation as appropriate. So, this study decided to use the model to test the mediating effect of families' social capital on students' education through shadow education.

\section{Intermediary Model of Family Economic Capital Influence on Students' Education Acquisitions}

This study measured family capitals influence on education acquisition. The intermediary model shows family economic capital influences education acquisitions of students (the results of standardized regression path coefficient of the model are shown in Figure 4). All path coefficients in the model past the significance level test except family economic capital influence students' performance. The joint significance test revealed that family economic capital had a significant mediating effect on students' performance and shadow education played a complete mediating role between family economic capital and students' performance.

The results of the model analysis suggest that the model is recursive with a sample size of 19,487 (the results of model fitting are shown in Table 4). All, except $\mathrm{CMIN} / \mathrm{DF}=11.87>5$, reached a good fit level indicating that the model can be well fitted with the actual observation data. The relationships between variables described in this model were reasonable and the parameters' estimation as appropriate. The model was used to test the mediating effect of families' economic capital on students' education through shadow education.

\section{Intermediary Model of Family Political Capitals Influence on Students' Education Acquisitions}

This study constructed the intermediary model to test family political capital influence on education acquisitions of students. The results of standardized regression of path coefficients show that all the path coefficients in the model have past the significance level test (are shown in Figure 5). Family political capital had a significant 


\section{Figure 1. Theoretical Model of Family Capitals Influencing Education.}

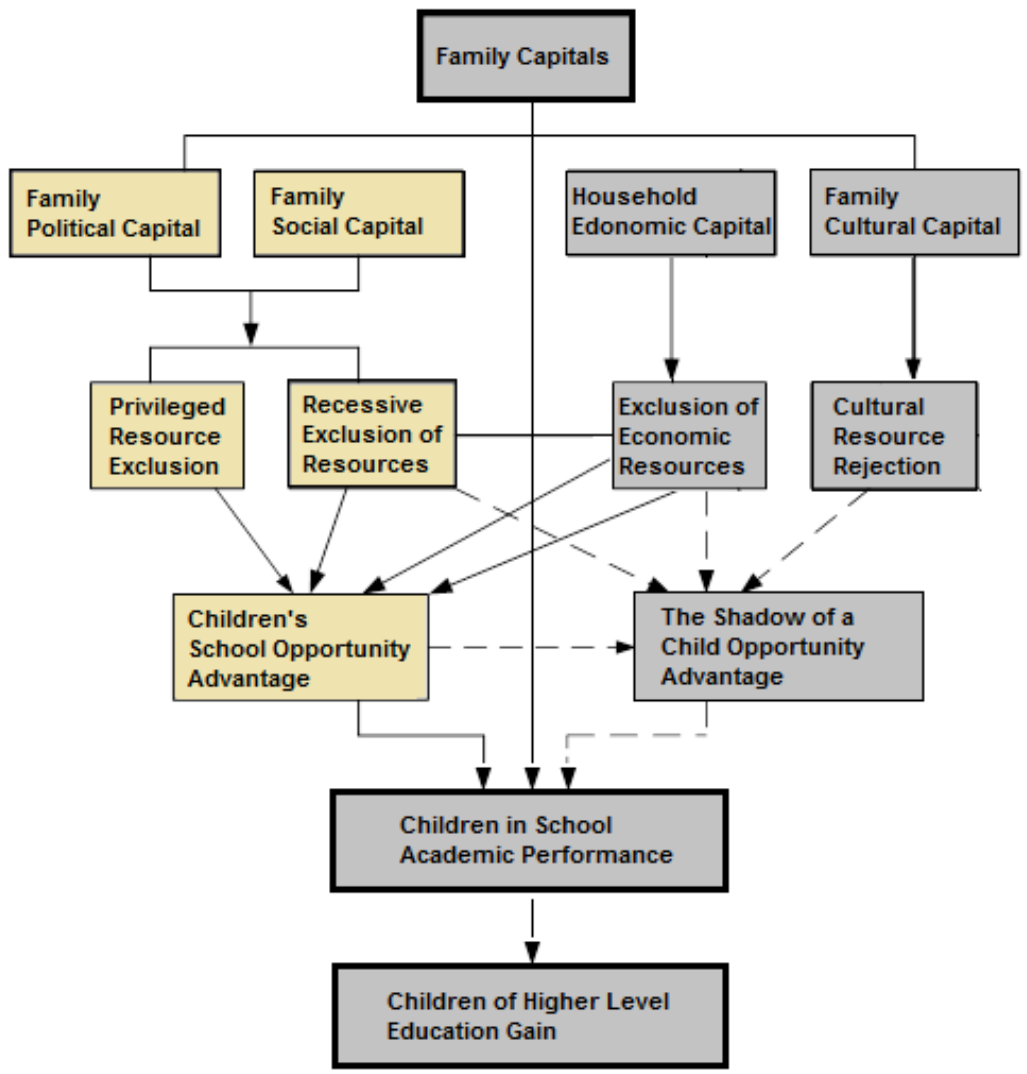

Figure 2. Multiple Intermediary Model of Family Cultural Capital Influencing Students' Education Acquisitions.

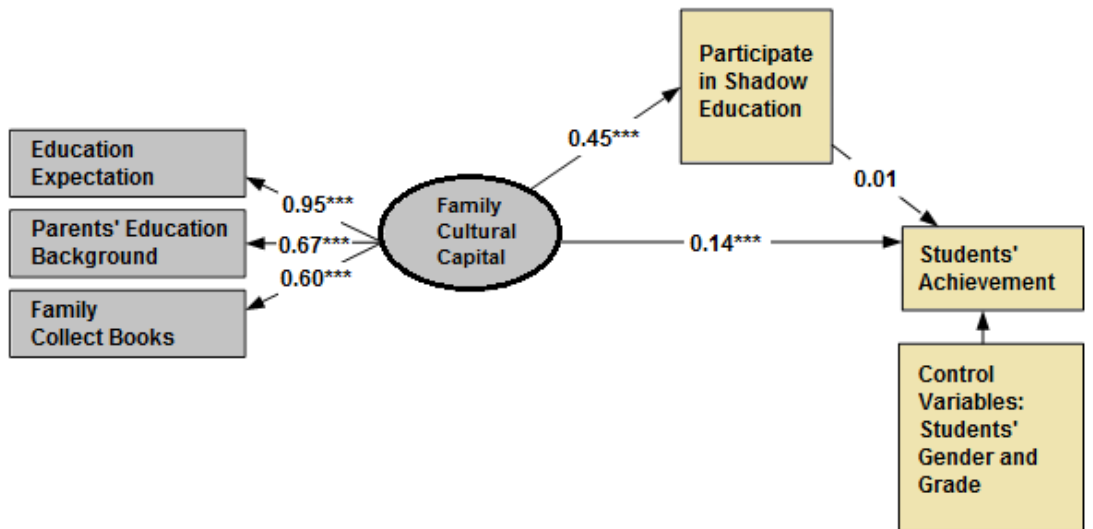

${ }^{* * *} \mathrm{P}<0.001,{ }^{* *} \mathrm{P}<0.01,{ }^{*} \mathrm{P}<0.05$ 
Figure 3. Model of Family Social Capital Influencing Students' Education Acquisitions.

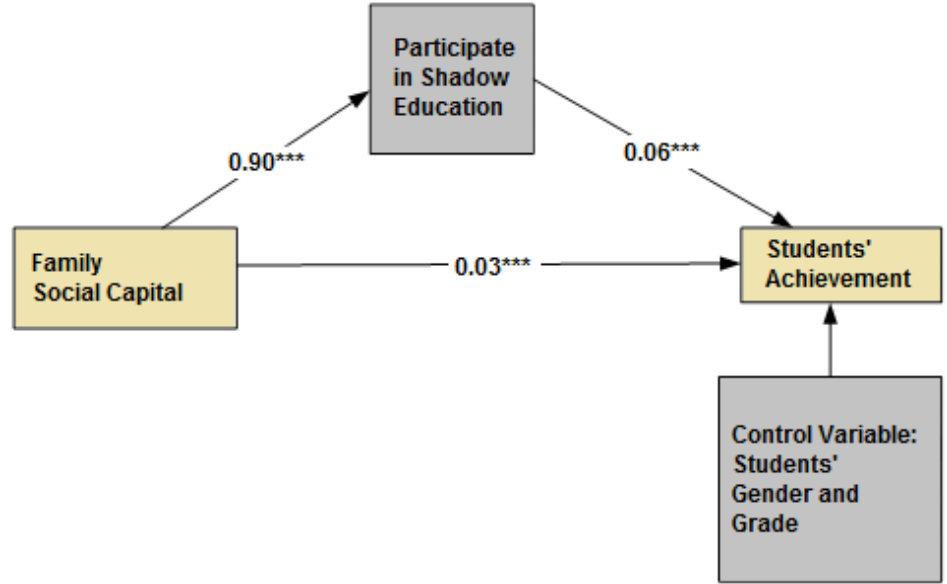

${ }^{* * *} \mathrm{P}<0.001,{ }^{* *} \mathrm{P}<0.01,{ }^{*} \mathrm{P}<0.05$

Figure 4. Model of Family Economic Capital Influencing Students' Education Acquisitions.

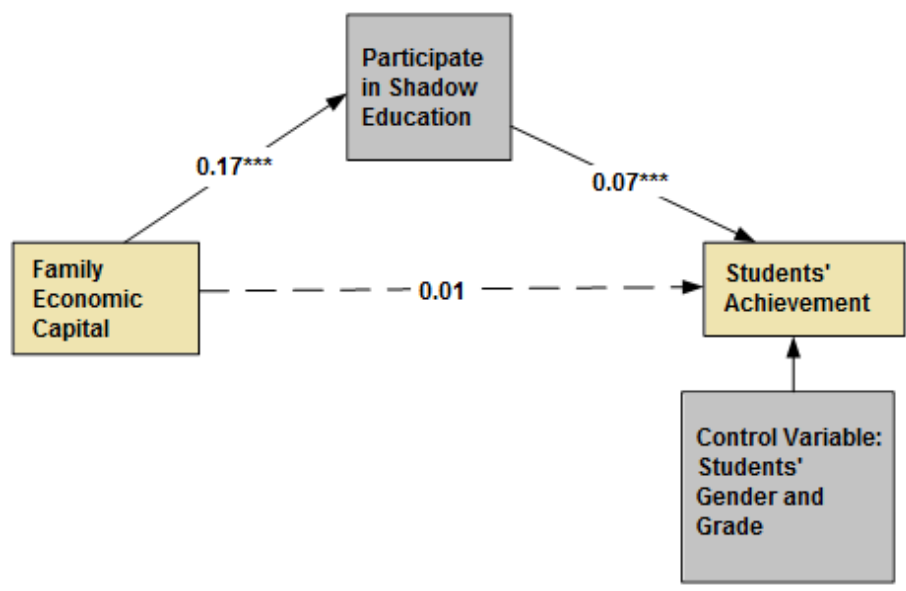

${ }^{* \star *} \mathrm{P}<0.001,{ }^{* *} \mathrm{P}<0.01,{ }^{*} \mathrm{P}<0.05$ 
Figure 5. Model of Family Political Capital Influencing Students' Education Acquisitions.

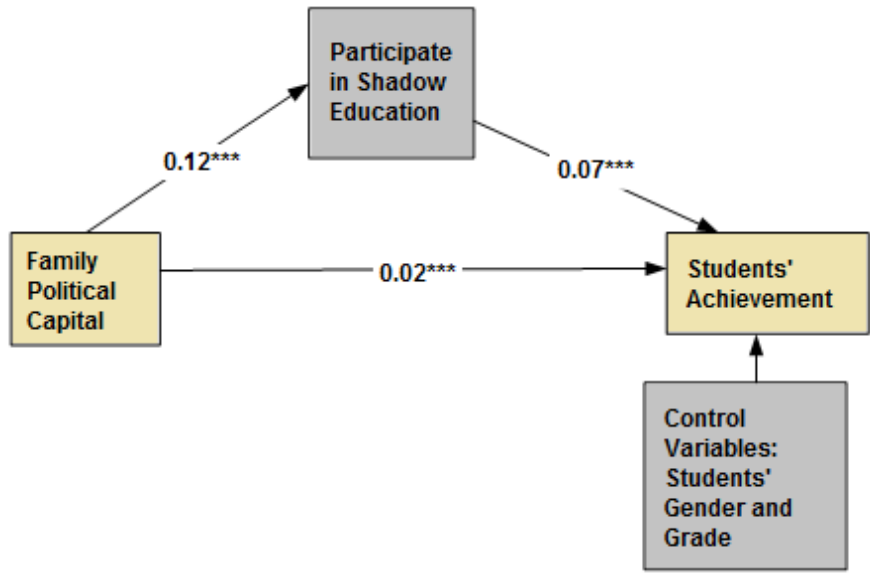

${ }^{* * *} \mathrm{P}<0.001,{ }^{* *} \mathrm{P}<0.01,{ }^{\star} \mathrm{P}<0.05$

Figure 6. Model of Family Capitals Influencing Students' Education Acquisitions.

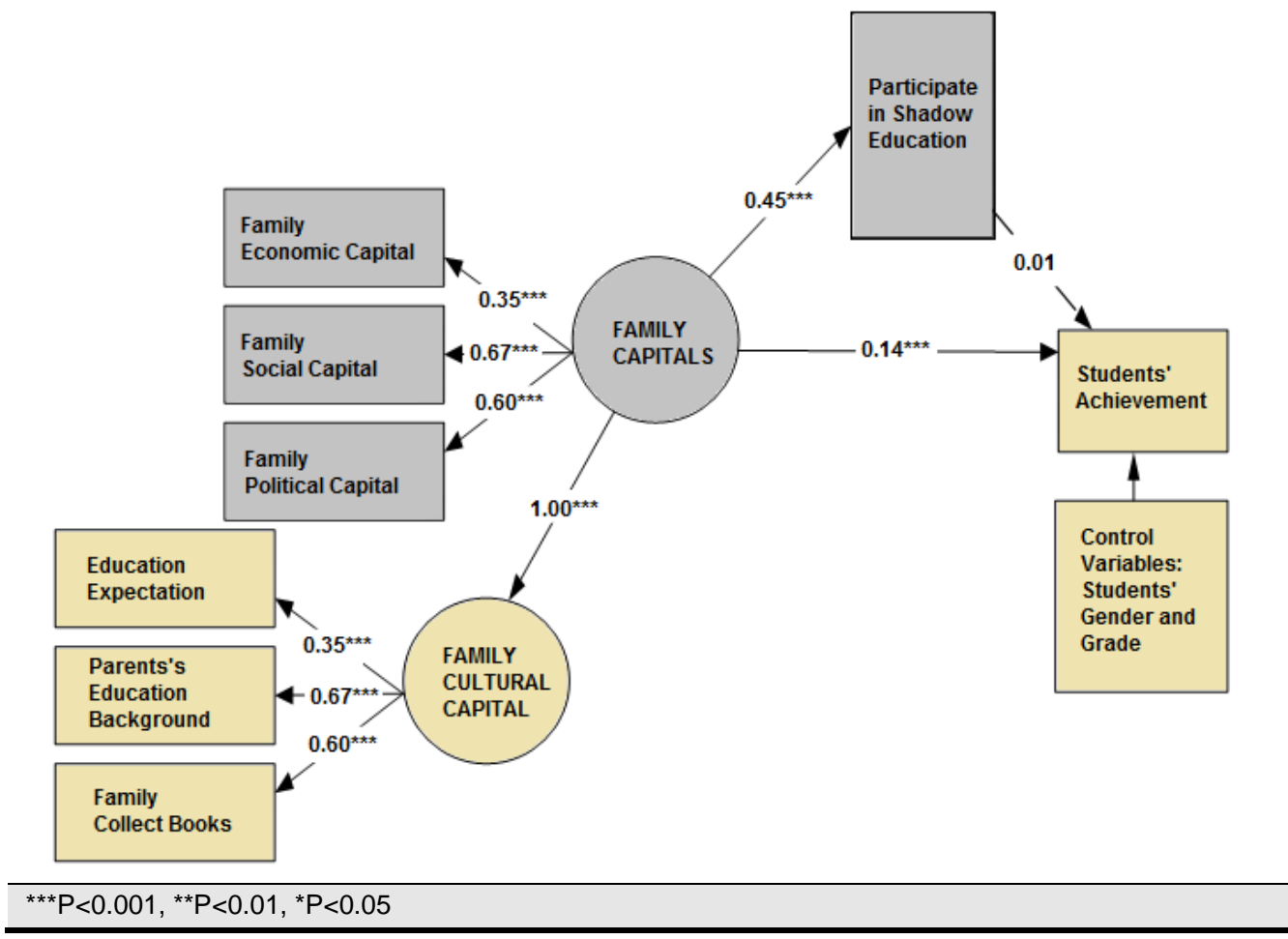


Xue. Family Capitals and Education Acquisitions.

mediating effect on students' performance and shadow education played a partial mediating role between family political capital and students' performance.

The results from the model analysis signified that the model is recursive with a sample size of 19,487. Except for CMIN/DF $=11.89>5$, all other fitting indexes have reached a good fit level indicating that the model can be well fitted with the actual observation data (he results of model fitting are shown in Table 5). The established model of family political capital influencing education was a good theoretical hypothesis model because CMIN/DF> 5 rejects theoretical model 1 and was the largest number of valid samples in the model statistically analyzes $(\mathrm{N}=19,487)$. The relationships between variables described in this model are reasonable and the parameters' estimation was appropriate. So it was decided to use this particular model to test the mediating effect of family political capitals on students' education through shadow education.

\section{Intermediary Model of Family Capitals Influence on Students' Education Acquisi- tions}

The results from the standardized regression path coefficients suggest that the model past the significance level test (Figure 6). Family capitals had a significant mediating effect on students' performance and shadow education played a partial mediating role between family capitals and students' performance.

The results of model analysis showed that the model was recursive with a sample size of 19,487 (see Table 6). Except for CMIN/DF $=35.52>5$, all other fitting indexes reached a good fit level.

\section{Conclusion and Policy Recommendations}

\section{Conclusion}

This paper combines school education and shadow education to investigate the influence of family capitals on junior high school students' education acquisitions. The following are the main research conclusions.

A family capital has a significant positive impact on education acquisitions on junior high school students, which, therefore, supports hypothesis 1 . In terms of all types of family capitals, family cultural, family social, and family political all have a direct and significant positive effect on junior high school students' education acquisitions. However, family economic capital has no significant direct impact on junior high school students' academic education acquisitions.

Participating in shadow education has a significant positive impact on education acquisitions of junior high school students, as well, thus, supporting hypothesis 2 . In the mediating effects of family capitals and total family capitals affecting students' education acquisitions, participating in shadow education had a significant positive impact on junior high school students' education acquisitions in all categories. 
Xue. Family Capitals and Education Acquisitions.

Shadow education plays a partial mediation intermediary role in the process of family capitals influencing students' education acquisitions. More specifically, family capitals influences students' education acquisitions by influencing their shadow education participation opportunities, and therefore, supporting hypothesis 3 of this study. Shadow education has different mediating effects among different types of family capitals and education acquisitions of students. It does not perform an intermediary role between family cultural capital and students' education acquisitions. The reason may be that families with high cultural capital can provide more direct guidance and motivation for their children's learning and such, families are less dependent on shadow education to improve children's academic performance. Shadow education also showed an intermediary role between family economic capital and students' education acquisitions. Families with high economic capital cannot provide direct support and motivation for their children to study on their own, but have the ability to buy more shadow education for their children and this largely relies on the shadow education to raise their children's academic performance. Results indicated that shadow education functions as an intermediary between family social capital and students' education acquisitions and political capital and students' education acquisitions. Families with high social capital and political capital not only provide direct support and motivation for their children's learning, but also rely on shadow education to improve their children's academic performance.

A family capital gets its status through the influence of both school education and shadow education on children's education acquisitions. Family capitals influence on junior high school students' education acquisitions through school education and shadow education systems displays the differences in opportunities. Families with higher education levels, ultimately, have their children attain higher social stratifications. Children growing-up in families with more capitals are more likely to enter the primary labor market, whereas, children coming from families with poor capital are more likely to enter the secondary labor market. Therefore, family capitals are transmitted from the fathers to the children. Intergenerational inheritance of family capitals is realized, and hence, this process of intergenerational inheritance of family capitals is seen in school education and shadow education. This educational social structure leads to solidifying of class right-up to the job market. Classic social reproduction theorists, such as, Coleman and Bourdieu, focus on the influence of family capitals on education acquisitions in schools. They elaborate on the mechanisms of education social reproduction in schools, but ignore the mechanisms of shadow education social reproduction. Currently, shadow education has become an important supplement to education in schools, globally. Shadow education acquisition is not only an important form of student education acquisition, but also, has an important impact on student school education acquisitions. Therefore, to only investigate the influence of family capitals on education acquisition on school education will eventually underestimate the influence of family capitals on education acquisitions of children and fully reveal the current mechanisms of education social reproduction. This study finds that the shadow education plays an intermediary role between family capitals 
Xue. Family Capitals and Education Acquisitions.

and education acquisitions. It also, ravels the joint mechanism of social reproduction between school education and shadow education, to a certain extent. In all, this study aims to assist in the development and improvement of the classic education social reproduction theory, for the current implementation of education fairness and the social mobility policy, in China, has certain significance.

The influence of shadow education on students' education acquisitions can be divided into short-term and long-term impacts. The short-term impact of shadow education on students' learning is mainly reflected in the promoting of students' academic performance in school. While, the long-term impact of shadow education on students' learning is attained in helping students to enter better schools.

Limited by data, this study only discusses the short-term impact of shadow education on the acquisition of family capitals and education. Therefore, we will analyze whether shadow education can help students to attend better schools. And, in subsequent studies, explore the long-term impact of shadow education between family capitals and education acquisition.

\section{Policy Suggestions}

Limiting the influence of family capitals on education acquisition and giving more emphasis to the role of education in promoting social mobility should become important responsibilities of governments around the world to achieve social equity. Based on the conclusions and discussions of this paper, the policy implications of this study are as follows.

Governments should take notice of the importance of shadow education and its influence on family capitals and students' education acquisitions. Governments can make policies, in particular for shadow education to reduce its impact and create more equal schooling. In recent years, Chinese governments at all levels have paid more attention to creating a fairer educational system that can control such dilemmas as shadow education. As well, new policies have been adopted to weaken the influence of family capitals. The hope is to lessen the role that the dominant class currently holds over the educational system and, thus, open new opportunities to disadvantaged groups.

In order to maintain their competitive advantage of entering the best schools, the dominant class has increasingly attached importance to use of the shadow education system and this has resulted in the exclusion of groups with less power. In other words, disadvantaged groups stuck in the inescapable intergenerational inheritance of family capitals are left with a school education and shadow education that is combined with social reproduction mechanisms. The result is severely weakened government policies on education and a damaged foundation for social equality.

At present, governments at all levels are fighting the logic that shadow education is an outcome of market behavior. Therefore, most lawmakers have a laissezfaire attitude towards shadow education and so generating a "if it isn't broke, don't fix it" approach to the current situation. However, governments should focus more on the intermediary role of shadow education and family capitals on students' education 
Xue. Family Capitals and Education Acquisitions.

acquisitions, forming initiatives to establish an educational system that will weaken the impact of shadow education through compulsory education fair policies.

The intermediary role of shadow education between family capitals and students' education acquisitions initiates the joint social reproduction mechanism of school and shadow education. Education's social reproduction function has also been further enhanced, making it easier for social strata to replicate and solidify. In order to break the class solidification and promote social equality, Chinese governments can also provide shadow education subsidies to families of junior high school students with poor academic performance and family capitals to weaken the negative impact of shadow education. Developed countries like Australia, England, France, Singapore and the United States have dealt with shadow education through measures, such as, remedial vouchers and allowances and tax breaks. Chinese governments can learn from these practices and bring forth explicit policies relevant to China to combat shadow education in the hopes to providing an equal opportunity education for all Chinese students.

\section{Notes}

$1 \quad$ The upper professional class includes: heads of government agencies, enterprises and public institutions, middle management personnel, middle and senior professional and technical personnel, cadres and civil servants of general government agencies, economic business personnel, private business owners and employees or above. The middle class includes: grass-roots management personnel, other professional and technical personnel/general technicians, employees of enterprises and institutions, technical workers, military police fire fighters, selfemployed/small business owners (8 employees or less). The lower occupational class includes: commercial and service personnel, non-skilled workers, agricultural, forestry, animal husbandry and fishery personnel, freelancers, unemployed and laid-off household workers.

2 Since this survey did not specifically ask parents about their political status, it asked respondents about their political status. However, since respondents may be people other than their parents, parents rather than parents' political status are used to measure family political capital. Statistical analysis shows that $92.5 \%$ of respondents are parents, $5.3 \%$ are grandparents, and the rest are other identities.

\section{References}

Bian, Y., Wu, X. \& Li, Lulu. (2008). Social stratification and mobility: The overseas scholar's advanced research on China. Renmin University of China Press. (in Chinese)

Bourdieu, P. (1989). Cultural capital and social capital. Zhang Renjie translation. Se- lected Basic Articles of Education Sociology Abroad. Shanghai: East China Normal University Press. (in Chinese)

Bray, M. (2012). Confronting the shadow education system: What government policies for what private tutoring? Edu Rev, 26(1), 132-133. 
Bray, M., Zhan, S., Lykins, C., Wang, D., \& Kwo, O. (2013). Differentiated demand for private supplementary tutoring: Patterns and implications in Hong Kong secondary education. Econ Edu Rev, 38(1), 24-37. (in Chinese)

Buchmann, C., Condron, D., \& Roscigno J. (2009). Shadow education American style: Test preparation, the SAT and college enrollment. Soc Force, 89(2), 435-461.

Carneiro, P. \& Heckman (2002). The evidence on credit constraints in postsecondary schooling. Econ J, 112(482), 705-734.

Chu, H. (2009). Background characteristics and personal factors of extracurricular tutoring families of primary and secondary school students in China. Edu Res Month1y,26 (12), 22-27. (in Chinese)

Coleman, J.S. (1988). Social capital in the creation of human capital. Am J Sociol, (supplement),94, 95-120.

Dang, H. A. (2007). The determinants and impact of private tutoring classes in $\mathrm{Vi}$ etnam. Econ Edu Rev, 26(6), 683-698.

Dobrzańsk, L.A., Gołombek, K., \& Hajduczek, E. (2000). Parental cultural capital and educational attainment in the Netherlands: A refinement of the cultural capital perspective. Sociol Edu, 73(2), 92111.

Fang, C., \& Feng, X. (2005). How distinction of social stratum affect the attainment of education: An analysis on split flows of education. Tsinghua J Edu, 26(5), 22-30. (in Chinese)

Guill, K. \& Bonsen, M. (2013). Leistungsvorteiledurch

Nachhilfeunterricht in Mathematik am beginn der sekundarstufeI? Unterrichtswissenschaft, 38(2), 117-133.

Guo, C., \& Min, W. (2006). The effect of economical and cultural capital on educational attainment in China. J Higher Edu, 27 (11), 24-31. (in Chinese)

Hong, Y., \& Zhao, Y. (2014). From capital to habitus: The class differentiation of family educational pattern in urban China. Sociol Stud, 29(4), 73-93. (in Chinese)

Hou, J. Wen, Z., \& Cheng, Z. (2004). Structural equation model and its application. Beijing: Education Science Press. (in Chinese)

Hu, Y., Fan, W., \& Ding, W. (2015). Does "shadow education" expand education in an unequal way? -- empirical study based on PISA 2012 Shanghai data. Peking Univ Edu Rev, 13(3), 40-59. (in Chinese)
James, R. (2000). Non-traditional students in Australian higher education: persistent inequities and the new ideology of student choice. Tertiary Edu Manag, 6(2), 105118.

Jiang, G., \& Yan, G. (2006). Correlation analysis on family capital and educational attainment disparity between rural and urban. Edu Sci, 22(8), 26-34. (in Chinese)

Katsillis, J., \& Rubinson, R. (1990). Cultural capital, student achievement and Educational reproduction: The case of Greece. Am Sociol Rev, 55(2), 270-279.

Li, C. (2003). Social political changes and inequality of educational opportunity. Soc Sci Chin, 24(3), 86-98. (in Chinese)

$\mathrm{Li}, \mathrm{Yu}$. (2006). The mechanism of institutional change and education inequality -- education acquisition of urban children in China (1966-2003). Chin Soc Sci, 27(4), 97-109. (in Chinese)

Liu, Z., \& Gao, Y. (2011). Family capital, social stratification and the attainment of higher education -- An empirical study based on Jiangsu province. J Higher Edu, 32(12) 18-27. (in Chinese)

Melot, L. (2010). Lemarché du soutiens colaire $[\mathrm{EB} / \mathrm{OL}]$. Retrieved from http://www.xerfi.fr/ etudes/7SME04.pdf.

Robinson, R.V., \& Maurice, A.G. (1985). Class reproduction among men and women in France: reproduction theory on its home ground. Am J Sociol, 91(2), 250280.

Siu, L. (2008). Issues and procedures in adopting structural equation modeling technique. J Appl Quantitat Method, 3(1), 76-83.

Smyth, E. (2009). Buying your way into college? Private tuition and the transition to higher education in Ireland. Oxford Review of Education, 35(1), 1-22.

Stevenson, D.L. \& Baker, D.P. (1992). Shadow education and allocation in formal schooling: Transition to university in Japan. Am J Sociol, 97(6), 1639-1657.

Sunderman, G.L. (2006). Do supplemental educational services increase for minority students? Phi Delta Kappan, 88(2), 117122.

Tan, J. (2009). Private tutoring in Singapore: Bursting out of the shadows. J Youth Stud, 12(1), 93-103.

Tansel, A., \& Bircan-Bodur, F. (2008). Private supplementary tutoring in Turkey: Recent evidence on its various aspects. Soc Sci Electronic Pub, 9(1), 162-171. 
Xue. Family Capitals and Education Acquisitions.

Teacherman, J. (2000). Parental cultural capital and educational attainment in the Netherlands a refinement of the cultural. Am Sociol Rev, 73(2), 92-111.

Tsang, M., Ding X., \& Shen, H. (2010). Urban-Rural disparities in tutoring of lowersecondary students. Edu Economy, 26(2), 7-11. (in Chinese)

Wen, Z., Zhang L., Hou, J., \& Liu H. (2004). Testing and application of the mediating effect TS. ActaPsychol Sinica, 49 (5), 614-620. (in Chinese)

Woessmann, A. (2010). Educational production in East Asia: The impact of family background and schooling policies on student performance. German Econ Re, 6(3), 331-353.

Wong, R.S.K. (1998). Multidimensional influences of family environment in education: The case of socialist Czechoslovakia. Sociol Edu, (1),1-22.

Xue, H. (2015). From school education to shadow education: Education competition and social reproduction. Peking Univ Edu Rev,13 (3), 47-69. (in Chinese)
Xue, H. (2016). Extracurricular tutoring, student achievements and social reproduction. Edu Economy, 32(2), 32-43. (in Chinese)

Xue, H. \& Ding, X. (2009). A study on additional instruction for students in cities and towns in China. Edu Res, 31 (1), 39-46. (in Chinese)

Zhang, G. (2015). Can money 'Buy' schooling achievement? Evidence from 19 Chinese cities. Chin Econ Rev, 35: 83-104. (in Chinese)

Zhang, Y. (2013). Does private tutoring improve students' national college entrance exam performance? A case study from Jinan, China. Econ Edu Rev, 32(1), 1-28. (in Chinese)

Zhou, J., \& Zou, X. (2016). Comparing the private tutoring options between students in China and the United State -- Evidences from 2012 PISA survey and investigation. Edu Economy, 32(2), 44-52. (in Chinese).

Received: 27 February 2019

Revised: 15 March 2019

Accepted: 21 March 2019

The Chinese version of this article has been published in Education \& Economics 2018; 34(4):69-78. The English version has been authorized for being publication in BECE by the author(s) and the Chinese journal.

薛海平. 家庭资本与教育获得: 基于影子教育中介效应分析. 教育与经济 2018; 34(4):69-78. 